\title{
Gatekeeping Prior to Point of Entry
}

\author{
Larry R. Reynolds
}

\begin{abstract}
Social work educators have an obligation to the profession to admit into its ranks those applicants judged to have the requisite knowledge, skills, and values for effectivepractice. Even though considerabledisagrement exists as to what those specifics encompass, there is a general sense that students should be monitored throughout the curriculum and that, by making admission decisions for students, the profession and ultimately the clients arebetter served. Thisstudy presents longitudinal data on an instrument utilized bya small BSW program acrossfivepre professional courses, yielding scores at mid-term and at the end of the semester that address students' compatibilities with the demands of the profession. Data are used in a feedback loop for assessing students compatibility with the profession prior to the initial point of entry into the major. Strengths and limitations of the study are addressed.
\end{abstract}

Keywords: BSW gatekeeping, student assessment, eval uation, longitudinal data

$\mathrm{P}$ rofessional academic programs across the nation articulate standards for admission into their courses of study, and these standards are readily found in such programs as nursing, education, and social work. The Council on Social Work Education (CSWE) requires in Accreditation Standard 5.0 that "the program has admissions criteria and procedures that reflect the programs' goals and objectives," (Council on Social Work Education, 2002, p. 39). Once these criteria and procedures have been established, it is incumbent upon the program to utilize those articulated standards in their decision-making processes for selecting students whom they perceive as meeting the standards and possessing the requisite qualities to successfully complete the course of study and move into the profession. This decision-making process, commonly known as "gatekeeping," is of concern for social work admissions committees and for students who endeavor to enter the profession. The concerns of admissions committees cover such realities as institutional pressures to maintain student enrollments and, thereby, ensuring a critical mass that guarantees the survivability of a program to determining which students actually meet the admissions criteria (McClelland, et al., 1991). Students applying for admission into the major are also concerned with whether they can meet the standards and what it may mean to them if they are denied admission into the major.

Larry Reynolds is Director of the Social Work Program at Marian College of Fond du Lac, Wisconsin, Fond du Lac, WI 54935.

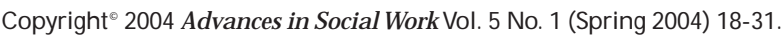

Indiana University School of Social Work. 
Social work faculty are frequently confronted with multiple and conflicting goals that create dilemmas and raise questions as to whether the admission decisions they make meet the intentions, goals, and objectives of the program. Social work programs also face the potential of creating lawsuits as a function of admission decisions. This is partly due to the difficulty the profession has in arriving at a consensus regarding the operationalization of the criteria for admission into the major (Younes, 1998; Morrow, 2000). It is difficult to define the qualities and characteristics that are requisite to the profession, and this subject generates much debate and controversy within the social work profession (Miller \& Koerin, 1998; GlenMaye \& Oakes, 2002). Nevertheless, it is imperative for programs to avoid utilizing arbitrary and capricious standards for admissions and to develop admission policies capable of differentiating between suitable and unsuitable applicants for the profession (Cole, 1991; Moore \& Urwin, 1991; Cole \& Lewis, 1993; Gibbs, 1994a; Miller \& Koerin, 1998). The core values of the profession, as identified in the preamble of the NASW Code of Ethics (1996), include "service, social justice, dignity and worth of the person, importance of human relationships, integrity, [and] competence," (p. 1). "A review of the Code of Ethics informs us of the importance of professional judgment as we make admission decisions in social work education" (Scott \& Zeiger, 2000, p. 410). This, in combination with CSWE accreditation standards and the program's admissions policies, sets a backdrop for decision-making related to admitting or denying students access to the professional program.

Students applying for admission to social work programs also experience considerable consternation. They invest time, energy, financial resources, and become invested in the application process and they are concerned about what it will mean if they are or are not accepted into a professional program. Once students are admitted into a social work program, they are likely to continue experiencing concerns as to whether they will be allowed to progress through the curriculum, enter a field internship, graduate, and successfully negotiate social work certification or licensing examinations.

As students progress through the curriculum, becoming more involved with student social work organization activities and understanding the values and ethics of the profession, they become more cognizant of the demands inherent in the profession. This added knowledge allows students to engage in the process of self-reflection regarding their compatibility with the profession. Through this process of self-reflection, it is not out of the ordinary for some students to determine that they are a mismatch for the profession. Likewise, as social work faculty learn more about a specific student and become more adroit at perceiving the student's strengths and liabilities, they may also determine the student possesses a significant level of incompatibility with the demands of the profession. Consequently, social work faculty may initiate a student's termination from the professional program. Either action typically creates some concern about litigation potential and social justice and raises value conflicts in faculty and students. Thus, social work programs throughout the nation are continually attempting to refine the process of identifying suitable students for the profession (Miller \& Koerin, 1998; Pelech, et al., 1999). 
It is this desire to attempt to refine the process of identifying suitable students for the profession that has led to the focus of this study. Specifically, a small BSW program developed an instrument that assesses students enrolled in pre-professional level courses on selected requisite behaviors for studying and practicing social work. Faculty observations of these behaviors tap into some of the qualities and characteristics perceived as being critical to successful social work practice. It is suggested that the data from this instrument provides yet another vehicle for social work students and program faculty to better assess a student's compatibility with the demands of the profession. It is argued that, through the use of this data prior to the actual point of entry into the student's major, the program and the profession are better served and informed about gatekeeping and admission decisions.

\section{LITERATURE REVEW}

Social work educators continue to debate the criteria for admission into the profession that allows for the safeguarding of the profession and ultimately the clientele who are the recipients of social services (Dunlap, et at., 1998; Magen, et al. (2000); GlenMaye \& Oakes, 2002; Kane, et al., 2002). One source that provides some guidance concerning the criteria for admission into the profession is the NASW Code of Ethics (1996). This document identifies ethical principles and standards to which social workers are held accountable. The Code of Ethics specifically points out that practitioners are to be competent to deliver services, attend to the well-being of those receiving social work services, and that educators are to evaluate students "in a manner that is fair and respectful," (NASW Code of Ethics, 1996).

CSWE is another source that provides guidance for admission into the profession. The CSWE 1994 Handbook of Accreditation Standards, $4^{\text {th }}$ edition, stated in Evaluative Standard 5 Student Development, 5.0 that "The program must clearly articulate and implement criteria and processes of student admission" (p. 87). Section 5.8 of this handbook requires that programs have "procedures for terminating a student's enrollment ... for reasons of academic and nonacademic performance" (p. 89). In 2002, CSWE published the $5^{\text {th }}$ edition of the Handbook of Accreditation Standards, which contains the new Educational Policy and Accreditation Standards (EPAS). It also specifies in Accreditation Standard 5, Student Professional Development, 5.6, that "The program informs students of its criteria for evaluating their academic and professional performance" (p. 40), and in 5.7, "The program has policies and procedures for terminating a student's enrollment in the social work program for reasons of academic and professional performance" (p. 40). Note the modification of language in the above statements concerning programs having policies for terminating students from the program. The 1994 standards called for students to be terminated for academic and nonacademic performance, while the 2002 standards call for termination for reasons identified as related to academic and professional performance. It will be recalled that Moore and Urwin (1991) advocated that "professional behavior is an academic requirement," (p. 11), and essentially suggested that in professional programs all behaviors are seen as academic and commingled into the educational process. 
The gatekeeping function in baccalaureate social work programs is an issuethat has received considerable attention from numerous authors (Moore $\&$ Urwin, 1991; Gibbs, 1994; Gibbs, 1994a; Younes, 1998; Moore, et al., 1998; Morrow, 2000). Recommendations for monitoring student readiness throughout the entire curriculum have been suggested (Moore \& Urwin, 1991), and these same authors have identified five areas of specific interest to the gatekeepers: (1) Grades, (2) Indications of students taking responsibility, (3) Effective communication skills, (4) Student's attention to social work values, and (5) Student's skills in handling feedback. Gibbs (1994b) noted in her study that there were not well researched screening criteria for assessing baccalaureatestudents' professional qualities. She notes that developing policies and procedures on these professional qualities was a difficult and contentious issue. Gibbs (1994a) stated “...educators have yet to devise policies that clearly and unimpeachably outline the qualities and characteristics that are requisite to effective professional practice" (p. 15). Hull, et al. (1994) also argues for the development of relevant outcome measures for social work education.

Younes (1998) suggests social work educators face considerable dilemmas in their role as gatekeepers. Programs need to balance student enrollment and survival of a program with questions regarding whether some students should be allowed to enter the profession. This research concurs that there is considerable difficulty in defining the characteristics that a candidate for the profession needs to possess to be qualified for the profession.

Moore, et al., (1998) uses case studies to describe problematic situations in gatekeeping and calls for innovative ways to identify social work students who may not be qualified to proceed in the profession. This study also articulated how corrective actions were taken with students, thereby supporting the gatekeeping function. Morrow (2000) points out that small baccalaureate programs face critical admission decisions, as they have the opportunity to know their students in more depth, but they also face the conflict of limited resources and institutional pressures to retain students. She noted three opportunities for programs to engage in gatekeeping and identified them as: (1) admission to the major, (2) admission to the field, and (3) sanctioning graduation lists. Bogo, et al. (2002) notes that even though students have graduated from accredited social work programs, that "educators do not appear confident that graduates are competent to practice" (p. 386). They further note that "if social work educators are unable to differentiate reliably between those students who possess the skills to practice and those who do not, we are failing in our critical role as gatekeepers for the profession" (p. 386).

In an effort to clarify the requisite characteristics that are compatible with entrance into the profession, Koerin and Miller (1995) conducted a study of MSW programs by assessing the reasons for terminating students for what were then classified as "nonacademic" reasons. They determined that violations of ethical standards, mental health or substance abuse problems, inadequate performance in the field, illegal behaviors, and disruptive classroom behaviors were reasons provided by graduate programs for terminating students from social work programs. These authors did not provide any information relative to the initial onset 
of these problematic behaviors; however, it would be unlikely that these behaviors would only manifested themselves during the graduate school experience. Dunlap, et al., (1998) examined the relationship between MSW program admission requirements and the subsequent relative academic success of the graduate student. Their findings suggested that the undergraduate grade point average (GPA) and Graduate Record Examination scores were positively related to academic performance. Miller and Koerin (1998) suggested that, at the MSW level, determining who is suitable to enter the profession requires continual monitoring throughout the educational process. They accurately recognize the interaction that exists among personal characteristics, life experiences, and "emphasis on the professional use of self" (p. 451). All of these authors note that social work educators, through continual gatekeeping activities, have an obligation to help students identify their compatibility with the demands of the profession.

Social work educators are cognizant that litigation may arise when decisions are made to deny students' entrance into the profession. Cole, (1991) and Cole and Lewis (1993) have provided educators with guidelines recommending due process for students and citing case law in which the courts have generally recognized and sustained faculty's professional judgment when functioning as a gatekeeper. The courts have also agreed that there is not a constitutional right to education, but that education is in fact a privilege.

Rhodes, et al., (1999) identifies the failure to enforce established gatekeeping standards as one of the elements that threatens social work education and the profession itself. They argue that, even though student enrollment has increased, there is little indication that a comparable number of students have been screened out of programs. Karger and Stoesz (2003) suggest that the growth in undergraduate, graduate, and doctoral programs has had an adverse effect on the profession, and that this growth has contributed to a reduction in the status of social work, kept salaries low, and has generally flooded the marketplace with an excess of social workers. They recommend that CSWE curtail its endorsement of new social work programs in an effort to enhance the quality of education and its graduates.

There continues to be much activity within the profession geared toward identifying instruments that can assist in the selection process of those students who seek access to the profession. GlenMaye and Oakes (2002) investigated the use of an instrument designed to objectively score an applicant's personal statement and relate this objective score to the student's effectiveness in the field experience. They found that reliability of the instrument was low, confirming the difficult task of assessing the suitability of applicants to social work programs. McClelland, et al., (1991) also found that social work faculty were highly idiosyncratic in their evaluations of BSW applicants and tended to streamline the gatekeeping criteria. Pelech, et al., (1999) studied several pre-admission variables and their relationship to problems students later had in the field experience. Interestingly, their results were contrary to what some social work educators and admission committees might have predicted. Their study revealed that students who tended to have more problems in the field were older, male, had more experience in social service delivery, were male, and were seen as less mature than students who did not demonstrate problems in the field experience. 
One element that is consistent in the literature is that on-going, continuous feed back to students concerning their performances in a variety of areas supports the idea that better judgments can be arrived at relative to student compatibility with the demands of the profession. The literature review also suggests admission decisions can be very challenging and that social work educators are generally looking for more effective means of gatekeeping and determining the quality of the applicants who request admission into the profession.

A gap remains in the gatekeeping literature with respect to establishing a methodology prior to the point of entry into the major for systematically providing undergraduate social work students with feedback on their behaviors that are viewed as critical to the demands of the profession. To address this gap, what follows is a description of a feedback mechanism utilized by a small BSW program with pre-professional level social work students. Feedback is provided to students at mid-term and again at the completion of the semester across five pre-professional level social work courses. These data form a benchmark by which students and faculty are better able to gauge the extent to which a student possesses behaviors deemed requisite to the profession. This longitudinal data provides useful feedback to students prior to their point of entry into the major, assisting the student and the decision-makers with an identification of a student's compatibility with the profession. These data are used initially in an advising role with students providing them formative feedback on some of their behaviors that have been identified as being essential to the practice of social work. These data are reviewed again at the time of the formal application to the major and, become part of the overall data set that is considered in rendering a summative decision relative to admission into the major.

\section{METHOD}

A small BSW program in the Midwest examined its gatekeeping procedures and reflected upon the experiences it had with students who had been admitted to the major and to the field experience. The formal gatekeeping process in this program is typical of BSW programs nationwide and begins during the second semester of the sophomore year when students submit a formal application for admission to the major. The second phase of the gatekeeping process commences during the second semester of the junior year when students submit a formal application for admission to degree candidacy and field internship. Students accepted into the field are then formally evaluated on at least two occasions each semester. The final gatekeeping mechanism is approving the students for graduation.

The program consulted with its community advisory group as advocated by Dalton and Wright (1999). This advisory committee is composed of social work practitioners at the BSW and MSW levels, social services organization administrators, a county government official who chairs the county social services committee, a county judge who presides over family and juvenile court, a community member who has received social work services, an undergraduate social work student, and social work faculty. This group suggested it would be desirable to develop a method whereby social work faculty gathered more systematic data on 
self-declared freshman and sophomore social work majors covering specific characteristics deemed requisite to the profession. The advisory committee then reviewed the professional literature and the program's objectives in relationship to the 12 foundation program objectives as articulated by EPAS. The advisory committee recommen ded that an instrument be developed that incorporated the general intent of the program objectives as articulated by EPAS, as well as including items the committee deemed essential for practitioners. Consequently, a 12item instrument was developed (see Evaluation of Student's Performance in Appendix I), which provided systematic data on student behaviors seen as requisite to the profession. The advisory committee, social work faculty, and social work students judged six of the 11 items on this instrument to have face validity with the objectives articulated by EPAS 3.0 Foundation Program Objectives (items $1,2,3,4,8$, and 10). The five remaining items were judged to be required by agencies, and were also seen as critical in the academy, since they are typically contained in social work syllabi (items 5, 6, 7, 9, and 11). Several of the latter items frequently impose a sanction on students for non-compliance, thus adding weight to their relevance.

Administration of this instrument yielded data on these essential behaviors which could then be used in a feedback loop with the students and program faculty to facilitate assessment of the students' compatibility with the requisites of the social work profession. Following training for administering the evaluation tool, social work faculty rated students in the classroom on these perceived critical elements of professional social work practice. A maximum score of 77 was possible and feedback was provided to students at two points in time-at midterm and upon completion of the pre-professional course. Data represented a longitudinal perspective of each student's compatibility with social work prior to being formally admitted into the professional foundation curriculum.

The five courses where the rating instrument was used were taught at the freshman and sophomore levels and were designated by the program as pre-professional courses and included community service, introductory social work, interpersonal skills, history of social welfare, and elementary statistics. Full-time social work educators or adjunct social work faculty who were practitioners in the community taught these courses. Students were typically enrolled in at least one of the courses per semester throughout their freshman and sophomore years. It was anticipated at the initiation of this study that not all students who enrolled in the social work program would have completed all five pre-professional courses contained within the program's curriculum. In fact, the students were at various stages of completing their pre-professional courses, as some had been waived out of a course, while others were transfer students who had completed equivalent coursework at another institution, and yet others had only recently changed their self-declared major to social work. In an effort to obtain an adequate sample for analysis, the program examined all of the data it had obtained on students over the five pre-professional courses. This examination yielded a maximum of 32 students who had completed at least three of the five courses, including introductory social work, history of social welfare, and elementary statistics. This provided six pairs of data points, two per course (a mid-term rating and a rating at the end 
of the course), and included ratings from both full-time and adjunct faculty. Data analysis was conducted with Statistix 8 software (2003) utilizing descriptive statistics, repeated measures ANOVA, simple linear regression, and correlation analysis.

\section{RESULTS}

The sample $(n=32)$ consisted of $90.6 \%$ females $(n=29)$ and $9.4 \%$ males $(n=3)$, with $59.4 \%(n=19)$ being characterized as traditional students and $40.6 \%(n=13)$ being characterized as non-traditional students. The ethnicity of the sample was $91 \%$ Caucasian $(n=29)$ and $9 \%$ minority $(n=3)$, including African-American, Hmong, and Latino students. The sample's age ranged from 20 to 49 years and, as can be gleaned from Table 1, below, $56.3 \%$ were single, $18.8 \%$ were single-parents, and $25 \%$ were married with at least one child.

\begin{tabular}{|c|c|c|}
\hline Table 1: Frequency Distribution of Parental Status \\
\hline Type of Status & Frequency & Percentage \\
\hline Single & 18 & 56.3 \\
\hline Single Parent & 6 & 18.8 \\
\hline Married & 8 & 25.0 \\
\hline Total & 32 & $100.0^{*}$ \\
\hline *rounding error \\
\hline
\end{tabular}

Table 2 shows the means and standard deviations of age by gender, parental status, and type of student.

\begin{tabular}{|c|c|c|}
\hline Table 2: Age of Student & \multicolumn{2}{|c|}{} \\
\hline Descriptor & M & SD \\
\hline Male & 32.0 & 12.767 \\
\hline Female & 26.172 & 7.7509 \\
\hline Traditional & 21.684 & 1.5653 \\
\hline Non-Traditional & 34.077 & 8.5192 \\
\hline Single & 23.222 & 5.9956 \\
\hline Single Parent & 26.333 & 4.2269 \\
\hline Married & 34.875 & 9.6130 \\
\hline
\end{tabular}

In comparing the ages of males and females in this sample, the females were about six years younger than the males; traditional students were around 12 years younger than non-traditional students; the singlestudent was around three years younger than the single parent and about 12 years younger than the married student.

The grade point averages by gender as determined at the close of the introductory course (GPA 1), upon completion of the history of social welfare course (GPA 2), and at the end of the elementary statistics course (GPA 3), respectively, are shown in Table 3. Male GPAs for all courses were higher than the GPAs for females, 
but due to the small number of males in the sample $(n=3)$, no statistical analysis on the differences between gender and GPA was undertaken. The non-traditional students' GPAs for all courses were higher than the traditional students: GPA $1=3.5141$ vs. 2.7445 , GPA2 $=3.4953$ vs. 2.7927 , and GPA3 = 3.4371 vs. 2.8593 ( $n=13$ for non-traditional and $n=19$ for traditional students).

\begin{tabular}{|c|c|c|c|}
\hline Table 3: Grade Point Average & \multicolumn{4}{l|}{} \\
\hline Descriptor & Course & M & SD \\
\hline Male & Intro GPA1 & 3.6136 & .5373 \\
\hline & History GPA2 & 3.6322 & .5237 \\
\hline & Statistics GPA3 & 3.6322 & .5237 \\
\hline Female & Intro GPA1 & 2.9996 & .6426 \\
\hline & History GPA2 & 3.0209 & .5172 \\
\hline & Statistics GPA3 & 3.0383 & .5018 \\
\hline
\end{tabular}

As might be predicted, the GPAs for married students and single parent students were higher than the single students (see Table 4).

\begin{tabular}{|l|c|c|c|}
\hline \multicolumn{1}{|l|}{ Table 4: Grade Point Average } & \\
\hline & GPA1 & GPA2 & GPA3 \\
\hline Married & 3.3134 & 3.3377 & 3.2419 \\
\hline Single Parent & 3.3989 & 3.2608 & 3.3319 \\
\hline Single & 2.8293 & 2.9020 & 2.9490 \\
\hline
\end{tabular}

The program was also interested in examining inter-rater reliability among the three faculty members who rated the students' behaviors. Two faculty were fulltime social work instructors and one was an adjunct faculty. Spearman correlations were computed using the final ratings from each class. The correlation between the final score from the introductory course and the history course was $r=57$; for the introductory course and the statistics course, it was $r=72$, and for the history course and statistics course, it was $r=70$. These correlations are all statistically significant at $\mathrm{p}<01$.

Table 5 reports the means and standard deviations for the mid-term and final scores across the three courses. A repeated-measures ANOVA revealed a significant change in the ratings across the three courses $F(5,155)=2.70, p<05)$. There were also statistically significant differences in scores between traditional and non-traditional students $F(31,155)=4.95, \mathrm{p}<01)$.

To locate where the differences existed between the mid-term and final scores, Tukey post-hoc analysis was conducted. Two significant differences were found: (1) between the final score in course 1 and the mid-term score in course 2 (the introductory and history course), and (2) between the final score in course 3 and the mid-term score in course 2 (statistics and history course). Tukey post-hoc was also conducted on differences between scores, and the differences were found in scores below 63. The effect size for differences among the courses was small at only $4 \%$, but much larger, $48 \%$, for differences between scores. 
Table 5: Scores for Mid-term and Final Across Three Courses

\begin{tabular}{|l|c|c|}
\hline \multicolumn{1}{|c|}{ Course } & M & SD \\
\hline Mid-term Course 1 & 68.000 & 8.4051 \\
\hline Final Course 1 & 69.656 & 7.6690 \\
\hline Mid-term Course 2 & 64.781 & 11.975 \\
\hline Final Course 2 & 68.031 & 5.9972 \\
\hline Mid-term Course 3 & 67.969 & 5.9323 \\
\hline Final Course 3 & 69.406 & 6.4150 \\
\hline
\end{tabular}

To locate where the differences existed between the mid-term and final scores, Tukey post-hoc analysis was conducted. Two significant differences were found: (1) between the final score in course 1 and the mid-term score in course 2 (the introductory and history course), and (2) between the final score in course 3 and the mid-term score in course 2 (statistics and history course). Tukey post-hoc was also conducted on differences between scores, and the differences were found in scores below 63 . The effect size for differences among the courses was small at only 4\%, but much larger, 48\%, for differences between scores.

Linear regression was used in an effort to predict a theoretical cutoff point for the final scores and the program's requisite GPA of 2.5 to be eligible to apply for admission to the major. The regression model for the introductory course yielded a predicted value of 67.573 on the rating scale, whereas, the history course yielded a predicted value of 64.145 and for the statistics course, the predicted value was 65.332.

Finally, it is interesting to note that the program's admission decisions fall into three categories: (1) admitted, (2) provisionally admitted, and (3) denied admission. The program examined the mean scores from the three pre-professional courses for students who had applied for admission to the major in relationship to the actual admission decisions made on these students. Findings indicated that students were admitted outright to the major when their ratings were 65 or higher. Provisional admission decisions were made on students with scores of 64 or 63 points and, in this limited sample, the means scores of 62 or less resulted in a denial of admission into the social work major.

\section{IMPLICATIONS}

Gatekeeping in social work programs is a vital function intended to identify those students who possess the requisite knowledge, skills, and values consistent with the demands of the profession, and who are adroit at providing competent services to clients. Social work educators must continue to identify methods that can strengthen the gatekeeping function. NASW and CSWE both articulate requirements for educators to engage in gatekeeping as part of their professional obligation to protect clients and the profession. The professional literature suggests that there is little agreement among social work educators as to what those specific characteristics are. Nevertheless, the literature suggests that, as social work students progress through the curriculum, they can benefit from continuous monitoring and feedback concerning their "fit" within the profession. This is based on 
the idea that feedback strengthens students' awareness of the requisite professional behaviors and assists them in judging their compatibility with the profession.

It is incumbent upon social work educators to assist students as early as possible in their educational experience to identify whether they possess the qualities that are compatible with the delivery of effective social work services, and then to aid students in the strengthening of those behaviors. The earlier this identification can be made, the better for the student, client, and ultimately, the profession. The longitudinal data from this small, non-representative sample lends support to the idea that pre-professional students used feedback from the instrument to assess their compatibility with the demands of the profession.

The expert panel assembled by the program consisted of its advisory committee, social work students, and social work faculty. The achieved consensus gives face validity to the identified behaviors that are consistent with the demands of the profession. The instrument is consistent with the intent of the NASW Code of Ethics, the 12 foundation program objectives detailed by EPAS, and the program's goal of graduating competent entry level practitioners. The reader is cautioned that the instrument described in this paper was designed only to assist the program and the student with identifying pre-professional behaviors viewed as conducive to the practice of entry level social work. It is beyond the scope of this paper to articulate the mechanisms by which the program monitors those students admitted into the major as they progress through the foundation curriculum and the field internship. Nevertheless, an instrument such as the one described in this paper becomes a mechanism for providing feedback to students prior to their admission into the major and ultimately benefits the student and the program's admissions decisions. Faculty and students utilize the data from this instrument in academic advising conferences regarding course selections and career goals (Moore, et al., 2003). In addition, as part of the application process for admission into the major, the program requires students to document how they make use of this data in their socialization to the profession and in their professional development plans.

Even though there is some utility promised by the instrument described here, it is obvious that there are several limitations to this study. The instrument has been utilized with only a small number of students, thus, no generalizations can be claimed. The program is still learning ways to incorporate this feedback into its gatekeeping obligations and, certainly, validation studies need to be conducted on theinstrument. As professional educators, we must continue to strengthen the profession by searching for methods that help identify which students are suitable to enter the social work profession.

\section{CONCLUSIONS}

The obligation of "guarding the gate" to the profession is a critical one. There continues to be a dearth of agreement among social work educators concerning what constitutes the qualities and characteristics that are requisite to the profession. Nevertheless, it is incumbent upon social work educators to explore ways to identify and test these requisite behaviors. Once the behaviors are identified, educa- 
tors must then use that information to help strengthen students' compatibilitities with the demands of the profession and to select individuals for admission into the profession who possess and develop those qualities. Social work educators have stressed that the life of the profession is tied to whom we select to enter our profession and provide services to clients. This is an awesome responsibility, and a modest attempt to contribute to the conceptualization and thinking about the gatekeeping process of admission decisions in a small BSW program has been presented here. Clearly, there is a need for ongoing research to articulate the requisite professional behaviors needed to be effective in delivering social work services and interventions. It is also critical to conduct studies to validate measurement tools purported to evaluate the preparedness of the students who seek admission into this profession. Finally, research should explore the "best practices" of pedagogy that develop and/or strengthen these requisite behaviors in our students.

\section{References}

Bogo, M., Power, R., Regehr, C., Globerman, J., \& Hughes, J. (2002). Evaluating a measure of student field performance in direct service: Testing reliability and validity of explicit criteria. Journal of Social Work Education, 38(3), 385-401.

Cole, B. (1991). Legal issues related to social work program admissions. Journal of Social Work Education, 27(1), 18-24.

Cole, B.S., \& Lewis, R.G. (1993). Gatekeeping through termination of unsuitablesocial work students: Legal issues and guidelines. Journal of Social Work Education, 29(2), 150-159.

Council on Social Work Education. (2002). Handbook of accreditation standards and procedures ( $5^{\text {th }}$ ed.). Washington, D.C.: Author.

Council on Social Work Education. (1994). Handbook of accreditation standards and procedures (4 $4^{\text {th }}$ ed.). Washington, D.C.: Author.

Dunlap, K.M., Henley, C., Jr., \& Fraser, M.W. (1998). The relationship between admission criteria and academic performance in a MSW program. Journal of Social Work Education, 34(3), 455-462.

Gibbs, P. (1994a). Screening mechanisms in BSW programs. Journal of Social Work Education, 30(1), 63-74.

Gibbs, P. (1994b). Gatekeeping issues in BSW programs. Aretê, 19(2), 15-27.

GlenMaye, L., \& Oakes, M. (2002). Assessing suitability of MSW applicants through objective scoring of personal statements. Journal of Social Work Education, 38(1), 67-82.

Hull, G. H., Mather, J. H., Christopherson, P. M., \& Young, C. M. (1994). Quality assurance in social work education: A comparison of outcome assessments across the continuum. Journal of Social Work Education, 30, 388-396.

Karger, H.J., \& Stoesz, D. (2003). The growth of social work education programs, 1985-1999: Its impact on economic and educational factors related to the profession of social work. Journal of Social Work Education, 39(2), 279-295.

Koerin, B., \& Miller, J. (1995). Gatekeeping policies: Terminating students for nonacademic reasons. Journal of Social Work Education, 31(2), 247-260.

Magen, R.H., \& Emerman, J. (2000). Should convicted felons be denied admission to a social work education program?Yes:*.Journal of Social Work Education, 36(3), 401-408.

McClelland, R.W., Rindfleisch, N., \& Bean, G.J., Jr. (1991). Rater adherence to evaluative criteria used in BSSW admissions. Aretê, 16(2), 10-18.

Miller, J., \& Koerin, B. (1998). Can we assess suitability at admission? A review of MSW application procedures. Journal of Social Work Education, 34(3), 437-453. 
Moore, L.S., \& Urwin, C.A. (1991). Gatekeeping: A model for screening baccalaureate students for field education. Journal of Social Work Education, 27(1), 8-17.

Moore, L.S., Dietz, T.J., \& Jenkins, D.A. (1998). Issues in gatekeeping. The Journal of Baccalaureate Social Work, 4(1), 37-50.

Morrow, D.F. (2000). Gatekeeping for small baccalaureate social work programs. The Journal of BaccalaureateSocial Work, 5(2), 65-80.

National Association of Social Workers. (1996). NASW Code of Ethics. Washington, D.C.: Author.

Pelech, W., Stalker, C.A., Regehr, C., \&Jacobs, M. (1999). Making the grade: The quest for validity in admissions decisions. Journal of Social Work Education, 35(2), 215-226.

Rhodes, R., Ward, J., Ligon, J., \& Priddy, W. (1999). Fighting for field: Seven threats to an important component of social work education. The Journal of BaccalaureateSocial Work, 5(1), 15-25.

Scott, N., \& Zeiger, S. (2000). Should convicted felons be denied admission to a social work education program? No! Journal of Social Work Education, 36(3), 409-413.

Statistix 8 (2003). Statistix 8. Tallahassee, FL: Analytical Software.

Younes, M.N. (1998). The gatekeeping dilemma in undergraduate social work programs: Collision of ideal and reality. International Social Work, 41(2), 145-153.

\section{Author's Note:}

Address correspondence to: Larry Reynolds, Marian College of Fond du Lac, 45 South National Ave., Fond du Lac, WI 54935, USA. E-mail: Ireynolds@mariancollege.edu

\section{Note:}

A version of this paper was presented at the Association of Baccalaureate Social Work Program Directors $21^{\text {st }}$ Annual Conference Reno, NV, October 29-November 2, 2003. 


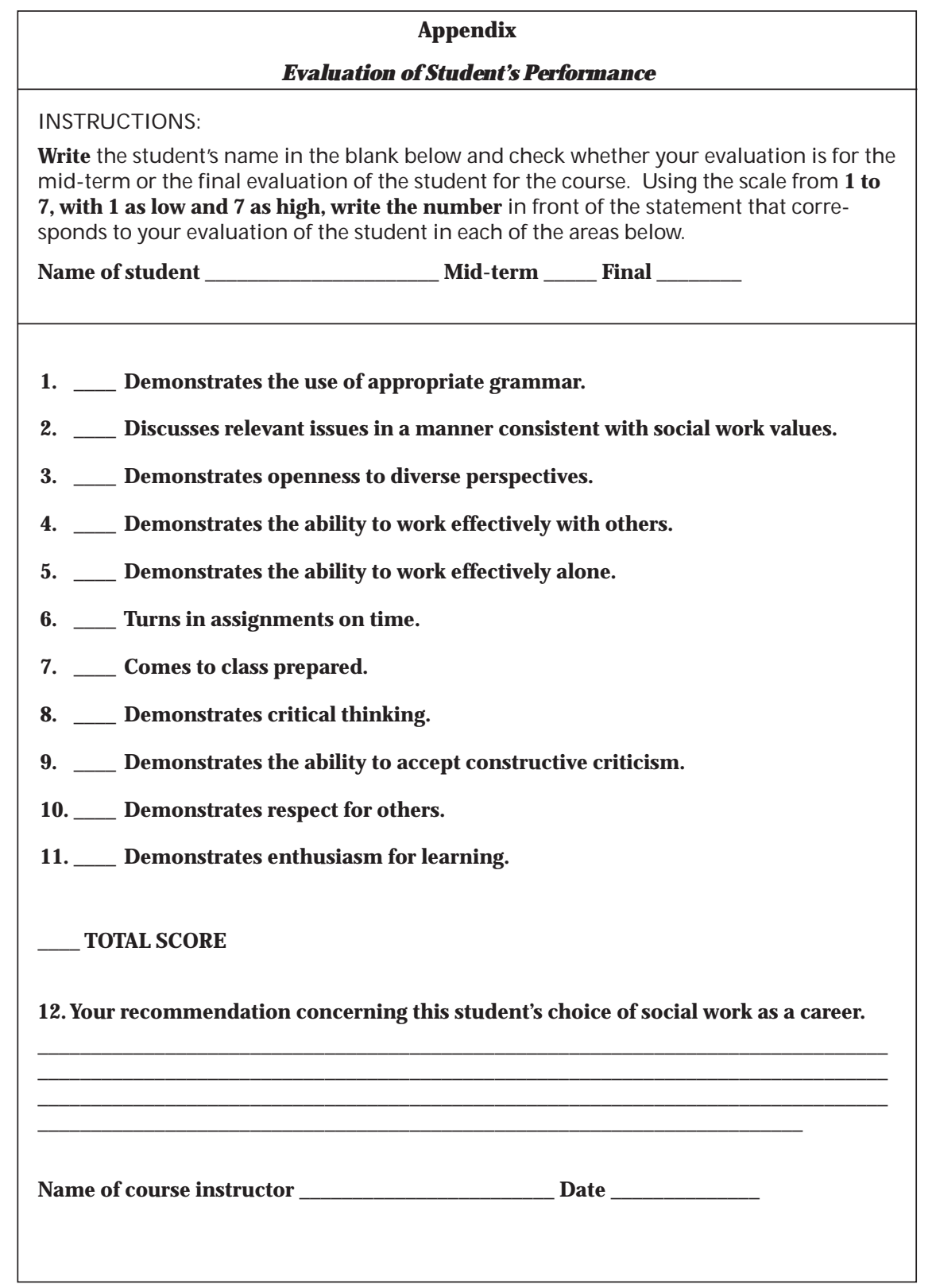

